\title{
Verificação da estanqueidade do leito de secagem em concreto armado de uma estação de tratamento de esgoto (ETE)
}

\author{
V.K. Ortolan ${ }^{1 ; 2 *}$, P.P. Ortolan ${ }^{2}$, D.C.M Arnold ${ }^{1}$ \\ *Autor de Contato: vkortolan@gmail.com \\ ${ }^{1}$ Instituto de Ciências Criativas e Tecnológicas, Escola de Engenharia Civil, Universidade Feevale, Novo Hamburgo- \\ RS, Brasil \\ ${ }^{2}$ Ortolan Engenharia, Campo Bom-RS, Brasil
}

\section{RESUMO}

Estações de tratamento de esgoto executadas em concreto armado são sistemas estruturais empregados para o tratamento de esgotos domésticos. Estas estruturas são expostas a agentes agressivos oriundos dos fluídos ricos em sulfatos. O esgoto doméstico não pode entrar em contato com o solo, por ser um fluido patogênico, sendo assim, as estruturas das estações de tratamento de esgoto, devem permanecer estanques durante todo o período da vida útil. O objetivo do estudo foi verificar se as manifestações patológicas existentes nas paredes dos leitos secantes, são prejudiciais à estanqueidade do sistema. Os resultados demonstraram que os danos patológicos existentes, geram perda de estanqueidade e que necessitam de tratamento, para impedir a passagem de águas residuais para o meio ambiente.

Palavras chaves: estanqueidade; reservatório de concreto; fissura.

\section{INTRODUÇÃO}


Estruturas de reservatório são elementos que objetivam o armazenamento de fluídos, sendo assim, demandam o atendimento ao desempenho à estanqueidade. A fissuração do concreto é uma das principais manifestações patológicas de uma estrutura de concreto armado destinada ao tratamento de águas residuais. De acordo com Thomaz (2007), em estruturas destinadas ao fim hidráulico, como reservatórios, as fissuras podem causar comprometimento do desempenho destes, devido à falta de estanqueidade do concreto, o que leva a redução da sua durabilidade.

Fissuras superficiais podem surgir no concreto durante o período de endurecimento, ocorridas por retração plástica (OLLIVIER e VICHOT, 2014). Os autores complementam que a retração plástica é uniforme em todo o volume do elemento de concreto e não acarreta risco de formação de fissuras em peças que permitem deformações. Por outro lado, quando em situação de impedimento, ocorre frequentemente uma parcela não desprezível de fissuração.

Deve ser destacado que as deformações ocorridas durante o período inicial de endurecimento do concreto, em decorrência das baixas propriedades mecânicas do mesmo, pois a influência da temperatura, oriunda do processo de cura do concreto, pode gerar alterações dimensionais por secagem do mesmo e, por consequência, pode causar alargamento e a ocorrência de novas fissuras (ZYCH, 2016).

Paredes de concreto armado são elementos esbeltos e de elevado comprimento, o que segundo Cánovas (1988), são facilmente suscetíveis aos efeitos de retração plástica. As fissuras nestes elementos costumam se apresentar em configuração vertical, espaçadas de modo equidistantes, com maiores aberturas na parte superior, bordo livre de restrição, e a medida que se aproxima da base da parede a fissura se fecha, ao ponto de desaparecer.

Além do calor de hidratação e em consequência dele, outras podem ser as causas da geração de tensões térmicas em concretos, resultantes de fissuras em estruturas de reservatórios. Thomaz (2007) cita as seguintes causas resultantes de fissuras em reservatório: o impedimento de deslocamento que a laje de fundo provoca nas paredes do reservatório, devido à exaustão do calor proveniente das reações químicas da pasta de cimento; o impedimento de retração da argamassa devido à perda de água para a atmosfera, por parte do agregado graúdo; o impedimento da argamassa de se retrair ao secar por parte da armadura; o fluxo de calor entre as camadas do concreto e entre o interior e a superfície externa da parede de concreto; a retração plástica na fase fresca do concreto nas primeiras horas; a retração hidráulica por causa da perda de água do concreto para o ar; a retração térmica por resfriamento, ou seja, há a perda de calor do concreto para a atmosfera.

Limites para a abertura de fissuras em estruturas de reservatório em concreto armado são cuidados que devem ser tomados em projeto, a fim de satisfazer o desempenho à estanqueidade dos líquidos e a durabilidade da estrutura. O fib Model Code (2010) estabelece requisitos para a abertura de fissuras conforme consequências da perda da estanqueidade, caso o vazamento for limitado em pequenas quantidades com o surgimento de manchas na superfície do concreto, deve-se limitar a abertura $\mathrm{em} \mathrm{w}_{\mathrm{k}}=0,2 \mathrm{~mm}$. Este limite também é recomendado para utilização de aditivo cristalizante na mistura do concreto, para correção de fissuras. Caso contrário, o limite de $\mathrm{w}_{\mathrm{k}}=0,1 \mathrm{~mm}$ se mostra mais adequado para estruturas de reservatórios de líquidos.

A norma EN 1992 (2006) estabelece que os valores limites para a abertura de fissuras devem ser definidos em função da razão da altura hidrostática do líquido $\left(\mathrm{h}_{\mathrm{d}}\right)$ com a espessura da parede $(\mathrm{h})$ do reservatório. Quando a razão é menor que 5 a abertura da fissura é limitada em $w_{k}=0,1 \mathrm{~mm}$, por outro lado, quando a razão for maior que 35 a abertura deve ser inferior a $w_{k}=0,05 \mathrm{~mm}$. É acrescentado ainda que o atendimento aos limites de abertura de fissura deve resultar na vedação eficaz em um período curto de tempo.

O procedimento de análise da abertura das fissuras indicado pela EN 1992 (2006), segundo Zych (2016), pode ser caracterizado como método simplificado, com resultados seguros para baixas 
pressões hidrostáticas. O autor acrescenta que a EN 1992 necessita de atualizações, principalmente em relação as condições de altas pressões.

A formação das fissuras, o espaçamento e distribuição podem ser influenciados pela quantidade de reforço estrutural, relação de restrição e insolação (SERUGA e ZYCH, 2015).

Stoffers (1978) estabelece que o espaçamento das fissuras pode chegar a compreender a relação de 1 a 1,5 vezes a altura da parede.

Com o intuito de confirmar o atendimento ao desempenho a estanqueidade, a norma EN 1992 (2006) recomenda a realização de testes de estanqueidade, como um procedimento seguro de verificação e certificação.

Diante do exposto o estudo tem como objetivo avaliar se as manifestações patológicas nas paredes de concreto armado desenvolvem prejuízos à estanqueidade à água em um reservatório de uma estação de tratamento de esgoto.

\section{MÉTODO}

Os procedimentos adotados para desenvolvimento deste trabalho estão descritos nos itens que seguem.

\subsection{Objeto de estudo}

O objeto de estudo é um reservatório em concreto armado semienterrado utilizado para o tratamento de esgoto, componente que integra o complexo da estação de tratamento de esgoto (ETE), localizada em região rural, com afastamento aproximado de $475 \mathrm{~m}$ da Rua Santos Dumont, na cidade de Rolante/RS, Brasil, a Figura 1 demonstra a visão geral da situação do empreendimento durante o estudo.

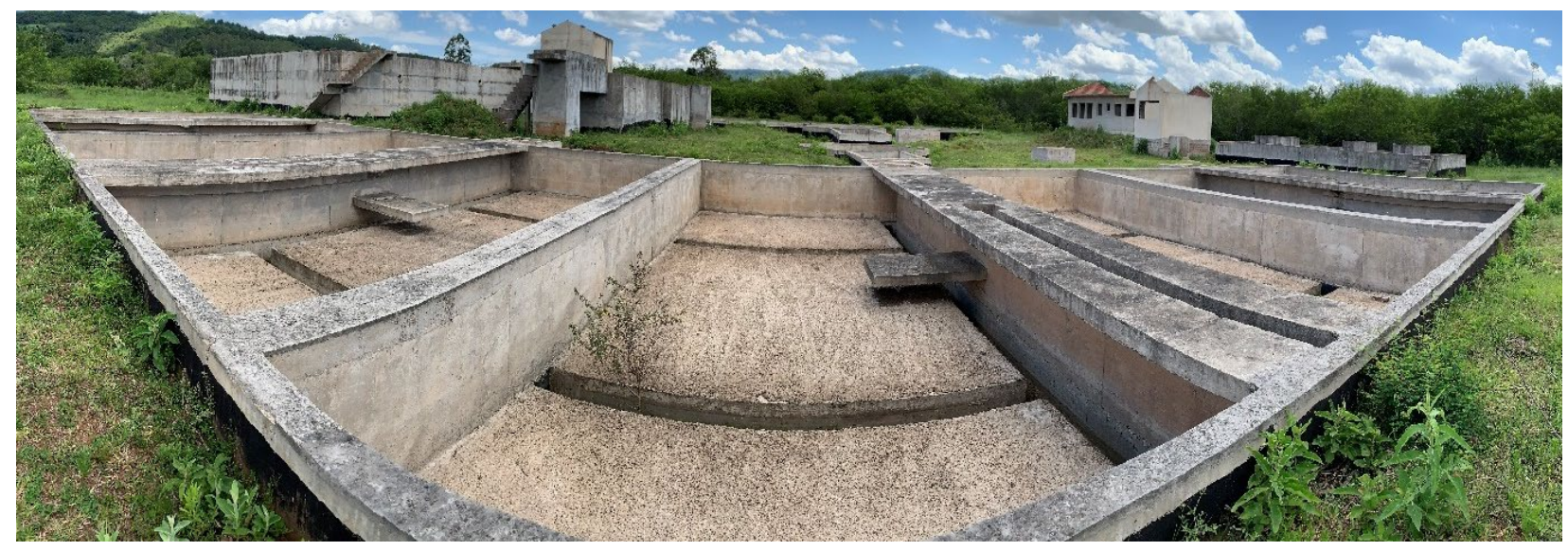

Figura 1. Visão geral da estação de tratamento de esgoto (ETE)

O complexo da estação de tratamento de esgoto é composto por diferentes etapas de tratamento, em uma destas etapas, o efluente é destinado a secagem em leitos de secagem dispostos em duas áreas na estação de tratamento. O estudo foi desenvolvido em um dos leitos de secagem (03), o qual está demarcado na Figura 2. O leito de secagem possui largura de 10,60m, comprimento de $11,40 \mathrm{~m}$ e profundidade de $1,30 \mathrm{~m}$, sendo composto por duas células com volume de $71,50 \mathrm{~m}^{3}$. 


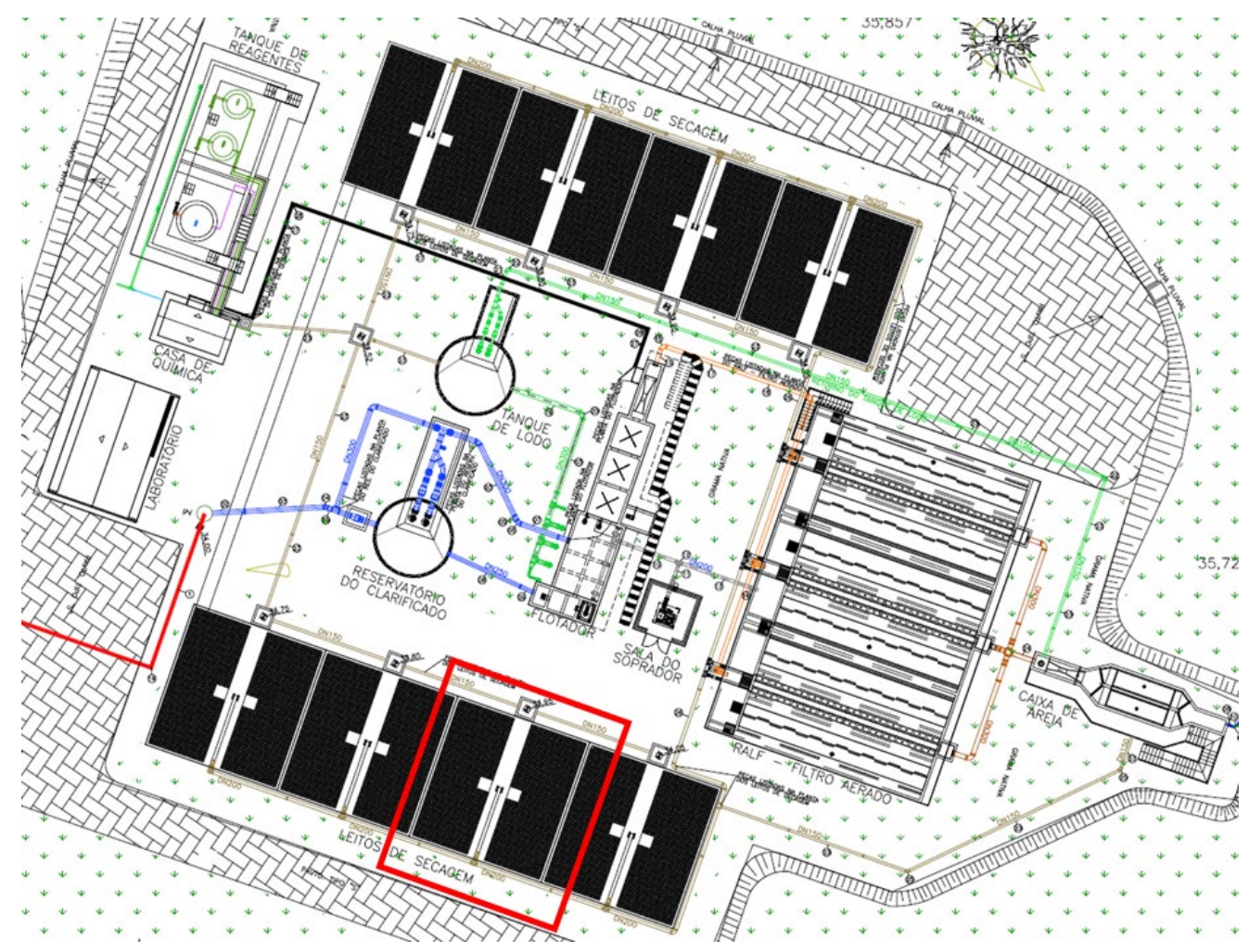

Figura 2. Leito de secagem objeto de estudo

\subsection{Verificação das manifestações patológicas}

As manifestações patológicas existentes na estrutura de concreto armado foram determinadas de modo visual e quantificadas com auxílio de trena e fissurômetro.

\subsection{Teste de estanqueidade}

Após a demarcação das manifestações patológicas existentes no leito de secagem em estudo, passou-se para a etapa de verificação da estanqueidade do tanque, a fim de analisar a existência de vazamentos na estrutura.

$\mathrm{O}$ teste de estanqueidade foi realizado de forma adaptada ao procedimento de ensaio descrito no manual técnico de orientação dos processos de construção e fiscalização de estações de tratamento de esgoto e reservatório em concreto armado da CORSAN (Companhia Riograndense de Saneamento).

O procedimento consistiu-se no enchimento e esvaziamento de água do leito secante, de forma lenta e gradual, com velocidade de elevação e rebaixamento do nível de água não deve superar 2 $\mathrm{cm} / \mathrm{h}$, conforme exigido pelo órgão regulador (CORSAN, 2011). No entanto, a velocidade de enchimento foi superior, por deficiência do equipamento de bombeamento disponível para o ensaio.

$\mathrm{O}$ enchimento do leito foi realizado com bomba de recalque a diesel com potência de $64 \mathrm{cv}$, o enchimento foi realizado apenas por um ponto, como demonstrado na Figura 3. 


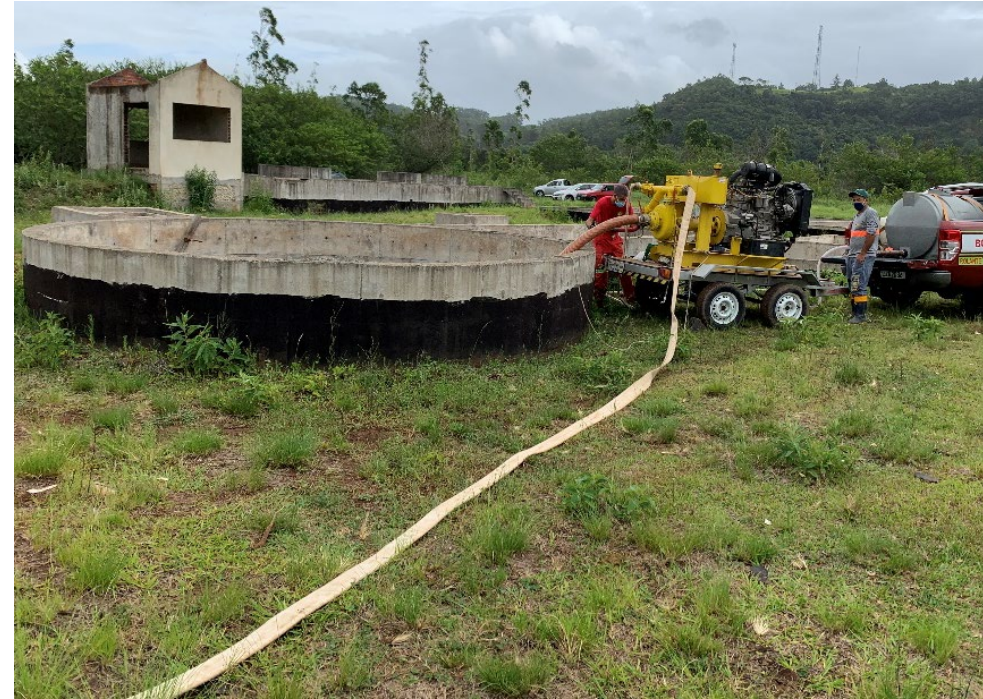

(a)

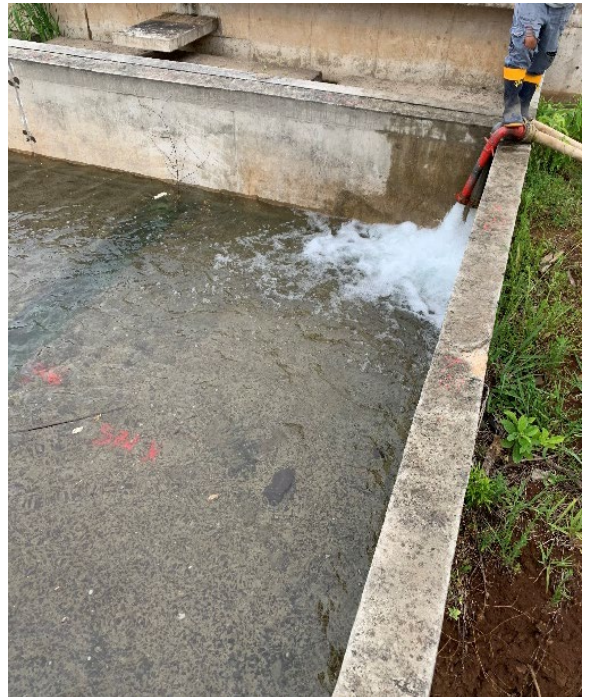

(b)

Figura 3. (a) bomba de recalque de água, (b) ponto de enchimento do leito

O nível máximo de água foi mantido para que os pontos com vazamentos fossem demarcados. $\mathrm{O}$ órgão regulador recomenda a manutenção do nível de água por 10 dias, no entanto, este período não foi mantido em decorrência da elevada velocidade da perda de estanqueidade do tanque.

O comportamento mecânico foi verificado pela variação de deslocamento com auxílio da medição da abertura das fissuras (Figura 4) e eventuais recalques foram acompanhados com medições por equipamento topográfico do tipo estação total.

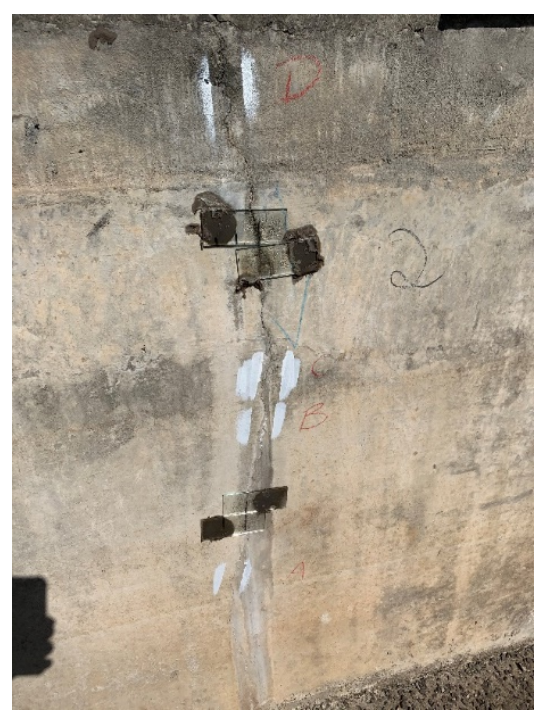

(a)

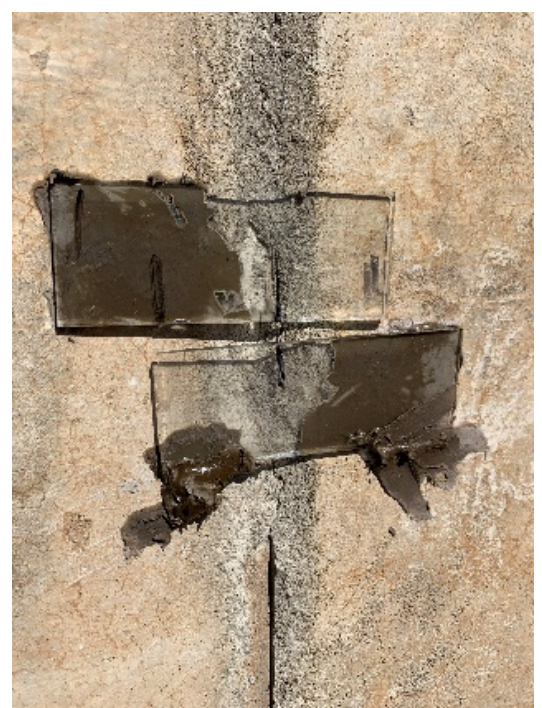

(b)

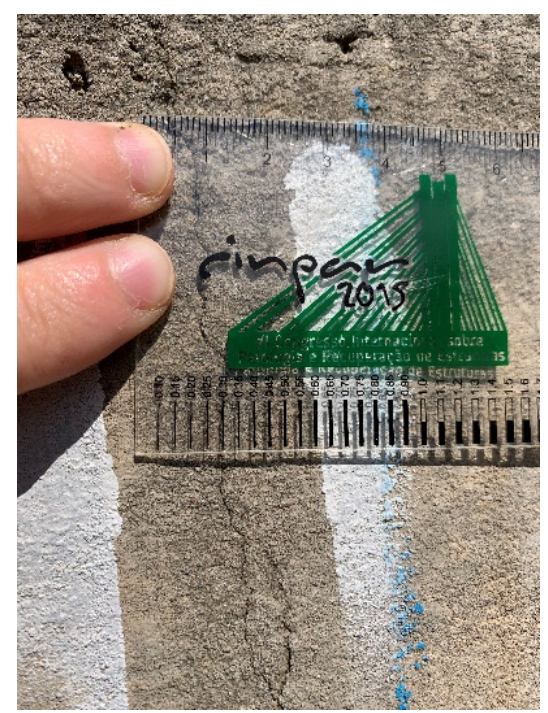

(c)

Figura 4. Verificação da movimentação de abertura das fissuras, a) visão geral dos locais analisados, b) placas de vidro, c) fissurômetro.

O leito em estudo foi demarcado com pontos estratégicos, com o intuito de apurar os deslocamentos durante o procedimento de ensaio, a Figura 5a apresenta croqui com os pontos de registro das movimentações da estrutura, enquanto que a Figura 5b e Figura 5c demonstram a baliza de medição do equipamento topográfico. 


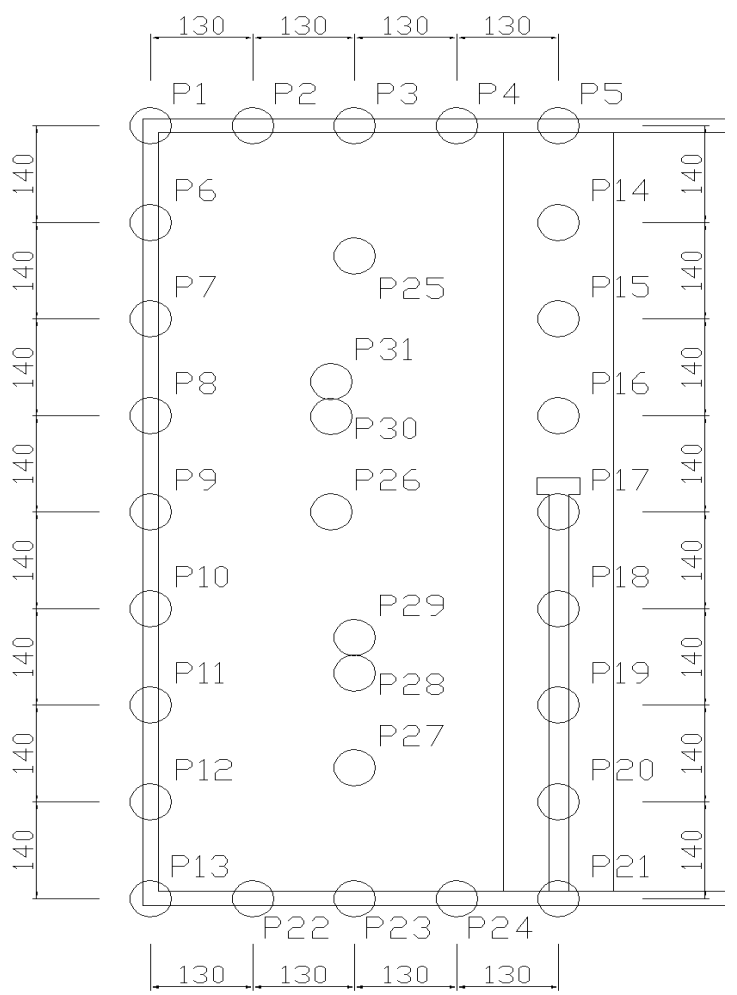

(a)

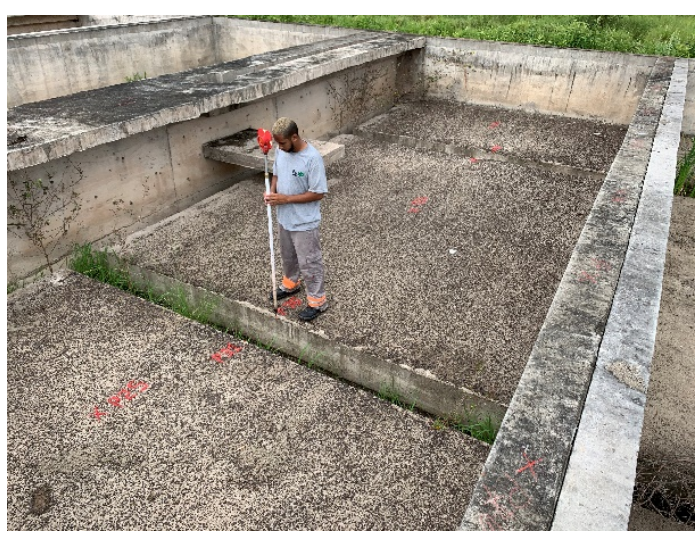

(b)

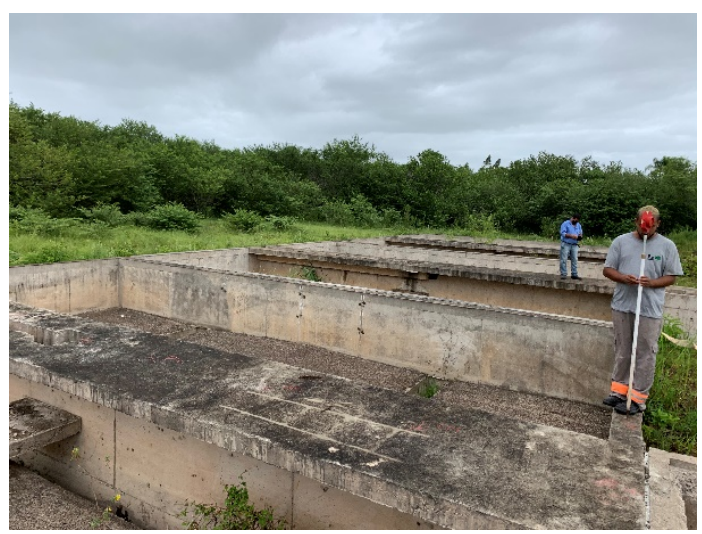

(c)

Figura 5. a) locais de medição das deformações do leito, b) e c) baliza de medição do equipamento topográfico

Foram registrados 31 pontos de medição sendo os pontos 1 a 24 nas paredes superiores e os pontos 25 a 31 o fundo do leito de secagem. As medições ocorrem antes do enchimento, sendo o tempo zero $\left(\mathrm{t}_{0}\right)$, após o período de enchimento $\left(\mathrm{t}_{1}\right)$ e última medição, 5 dias do término do enchimento $\left(\mathrm{t}_{\mathrm{f}}\right)$ do leito de secagem com água.

\section{RESULTADOS}

Os resultados obtidos no decorrer do procedimento técnico de verificação das manifestações patológicas no leito de secagem da estação de tratamento de esgoto executada em concreto armado, estão expressos nos tópicos subsequentes.

\subsection{Manifestações patológicas observadas}

Foram observadas manifestações patológicas de fissuras nas paredes de maior lado, parede 3 e 4, conforme representadas na Figura 6b. Nas paredes de menor lado não foram observadas fissuras. As formações das fissuras visualizadas são verticais e compreendem toda a espessura e altura da parede, estão regularmente espaçadas entre si, como demonstrado na Figura 6b. 


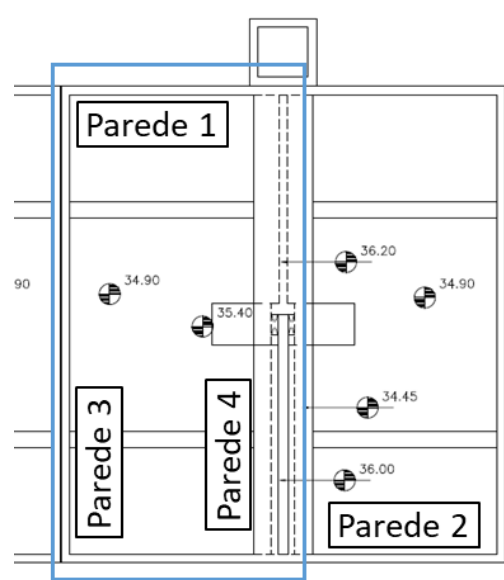

(a)

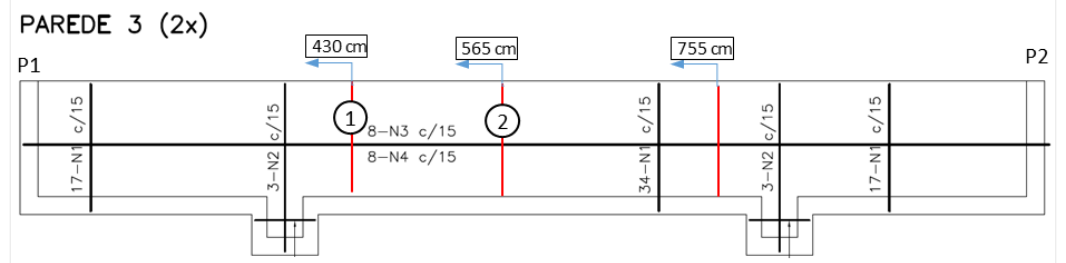

PAREDE 4

P1

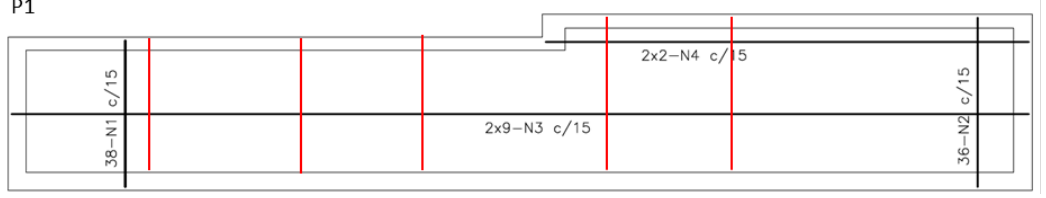

(b)

Figura 6. a) Representação dos locais analisados no leito de secagem, b) locais nas paredes com fissuras

As fissuras 1 e 2 manifestadas na parede 3 são demonstradas na Figura 7, respectivamente, sendo possível observar que as mesmas percorrem toda a altura da parede.

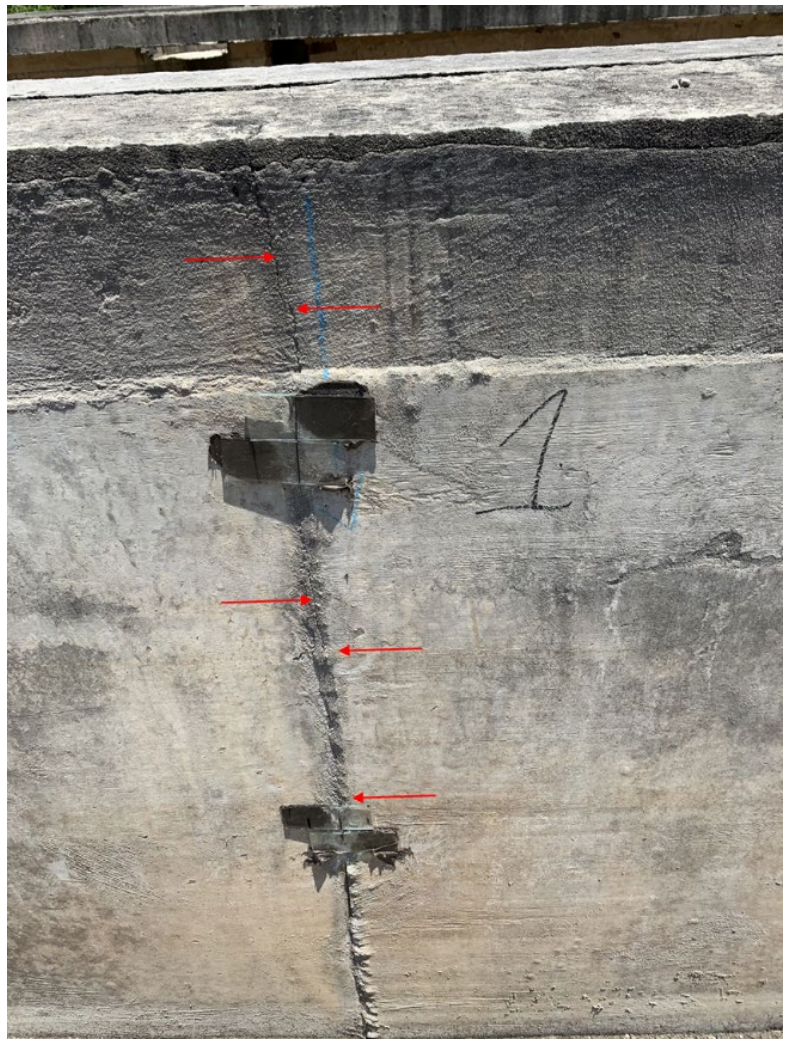

(a)

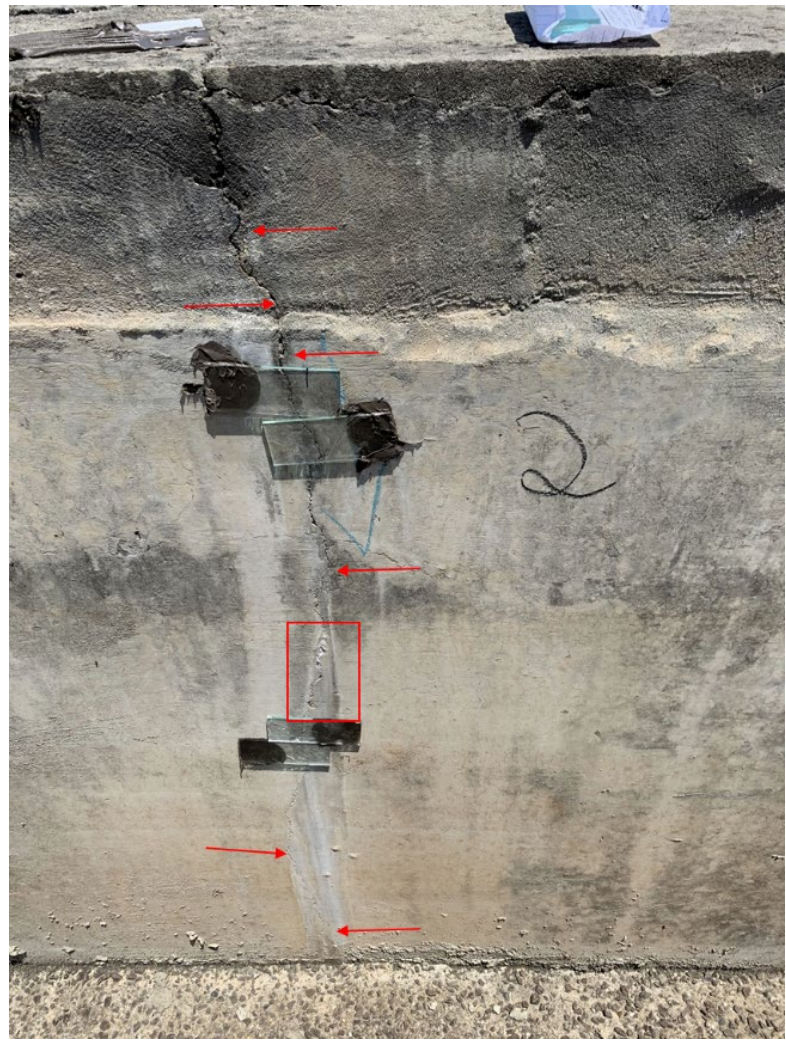

(b)

Figura 7. (a) Fissuras 1 e (b) 2 verticais na parede 3

A abertura das fissuras foram registras ao longo de todo o comprimento e os resultados das aberturas das fissuras 1 e 2, são organizados na Tabela 1. A Figura 8 demonstra a medição da abertura da fissura na borda superior e na região central com régua graduada do tipo fissurômetro. 
Tabela 1. Abertura das fissuras 1 e 2 ao longo do comprimento na parede 3 , unidade em mm

\begin{tabular}{|l|c|c|}
\hline & Fissura 1 & Fissura 2 \\
\hline Borda superior (livre) & 0,35 & 0,5 \\
\hline Região central & 0,45 & 0,45 \\
\hline Borda inferior & 0,3 & 0,3 \\
\hline
\end{tabular}

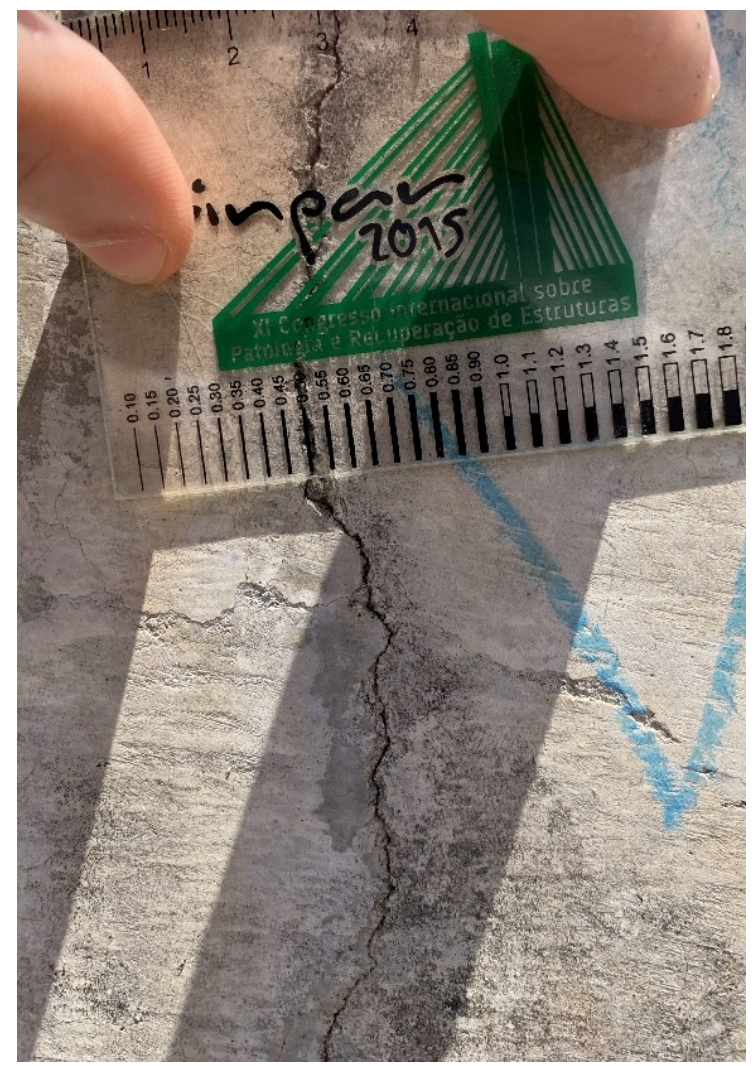

Borda superior

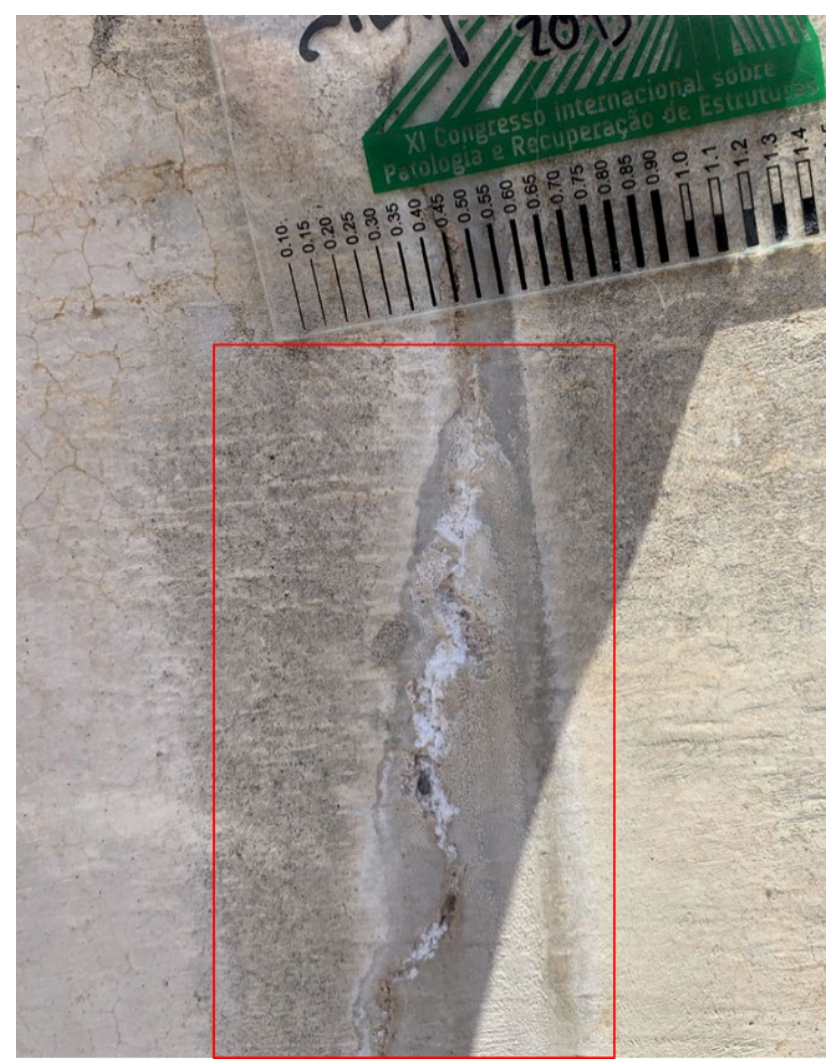

Região central

Figura 8. Determinação da abertura da fissura

Ao observar os resultados da medição da abertura das fissuras, foi possível destacar que, de modo geral, as fissuras apresentaram maior abertura nas regiões próximas a borda superior e à medida que a fissura percorre a parede no sentido do piso, a abertura da fissura diminui.

$\mathrm{Na}$ fissura 2, em região próxima à borda superior da parede, possui abertura aproximada de 0,50 $\mathrm{mm}$ e em região central da parede, a fissura possui abertura aproximada de $0,45 \mathrm{~mm}$. Indicando com isto, que a fissura possui menor abertura nas regiões próximas a base da parede, constatação também mencionada por Cánovas (1988), a qual caracteriza o diagnóstico de fissuras por retração plástica com impedimento.

Na Figura 8, como destacado pelo retângulo vermelho, em um determinado ponto da fissura, foi observado deposição de cristais na cor branca na borda da fissura próxima a região central da parede, a manifestação patológica foi caracterizada como lixiviação, pelo acúmulo de sais solúveis formados pelo transporte do carbonato de cálcio pela infiltração de água pela fissura.

Além das fissuras, foram observadas na parede 4, em regiões próximas a base da parede, segregação das partes constituintes do concreto, como demonstra a Figura 9. 


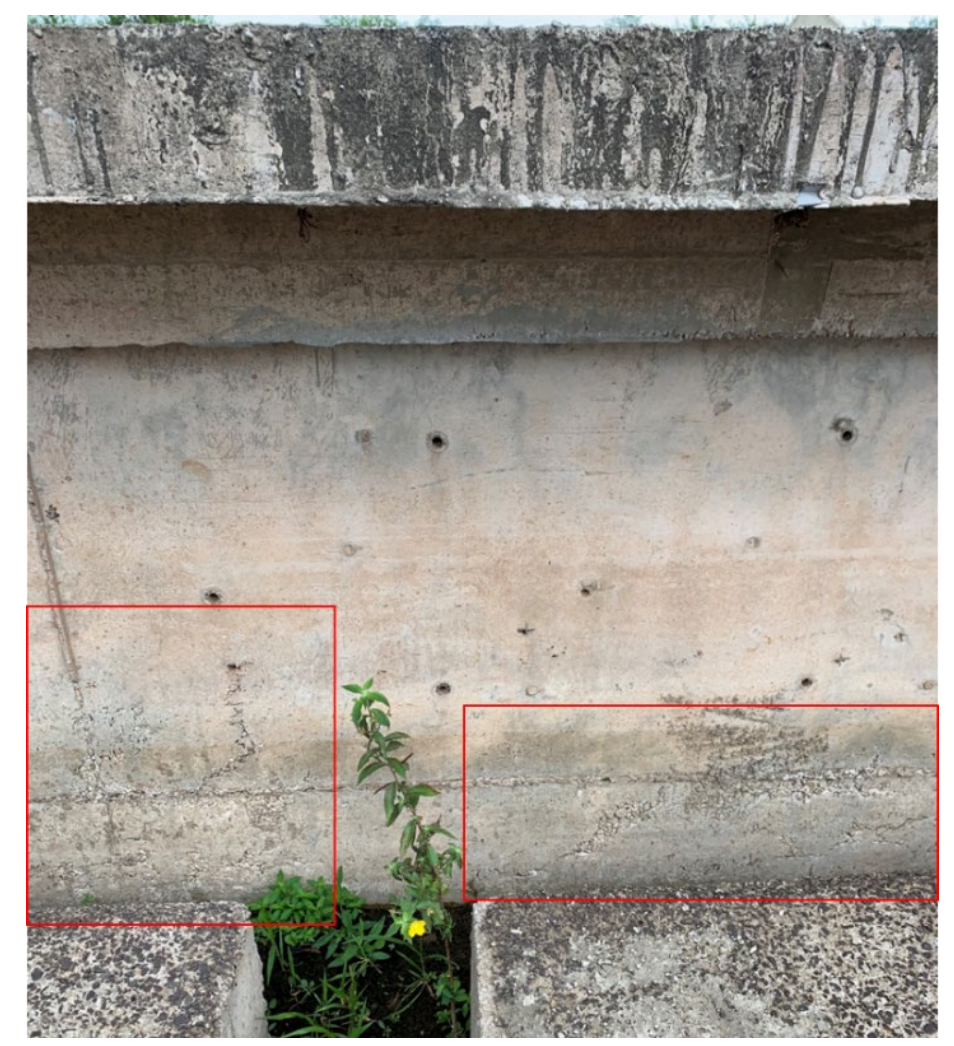

Figura 9. Segregação das partes constituintes do concreto

Nos locais destacadas pelos retângulos vermelhos, são indicadas as regiões da parede com segregação do concreto. Esta manifestação patológica foi originada pelo processo deficiente de adensamento do concreto no instante da concretagem da parede, gerando ninhos de concretagem. Após levantamento das manifestações patológicas no leito de secagem em estudo, o teste de estanqueidade foi realizado.

\subsection{Teste de estanqueidade}

O teste de estanqueidade foi finalizado com nível máximo de água em $60 \mathrm{~cm}$, como demonstrado na Figura 10, por motivos de paralisação do equipamento de recalque.

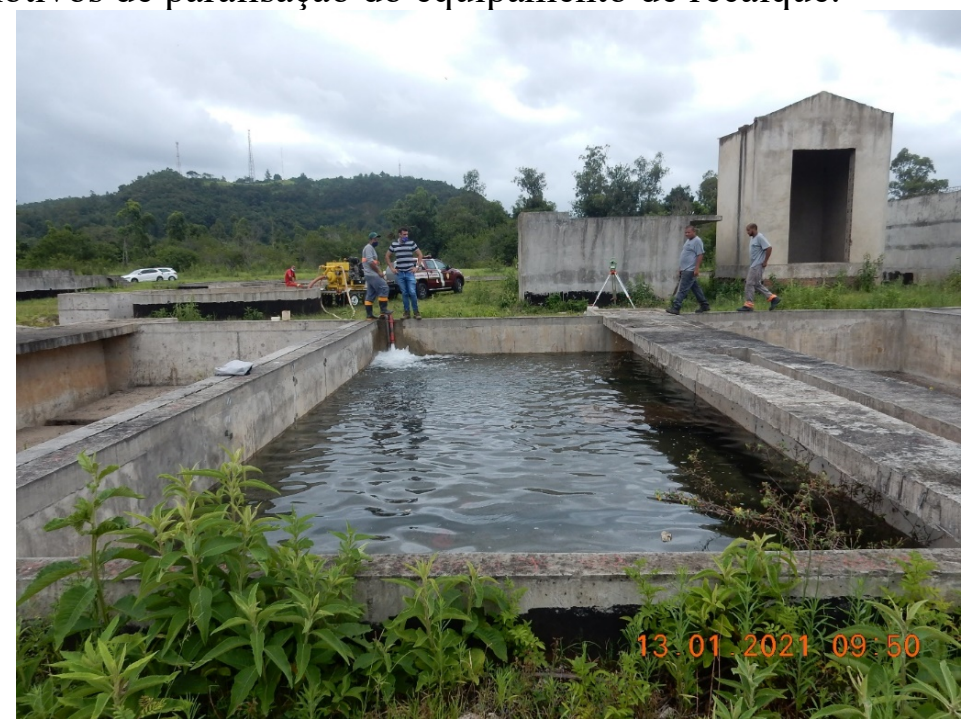

Figura 10. Nível máximo do enchimento do tanque 
O nível de $60 \mathrm{~cm}$ foi adotado como nível máximo de ensaio, este nível foi mantido até o esvaziamento, por completo, do tanque. Importante destacar que em decorrência do acesso limitado à equipamentos de recalque, que a manutenção do nível de água não foi mantida, tampouco o procedimento de esvaziamento, que não pode ser desenvolvido.

Durante e após o término do enchimento do leito, foram realizadas inspeções em todos os pontos visíveis do leite de secagem, com o intuito de identificar possíveis vazamentos.

Junto a parede 4, foram observados pontos de vazamentos, alguns destes são demonstrados na Figura 11.

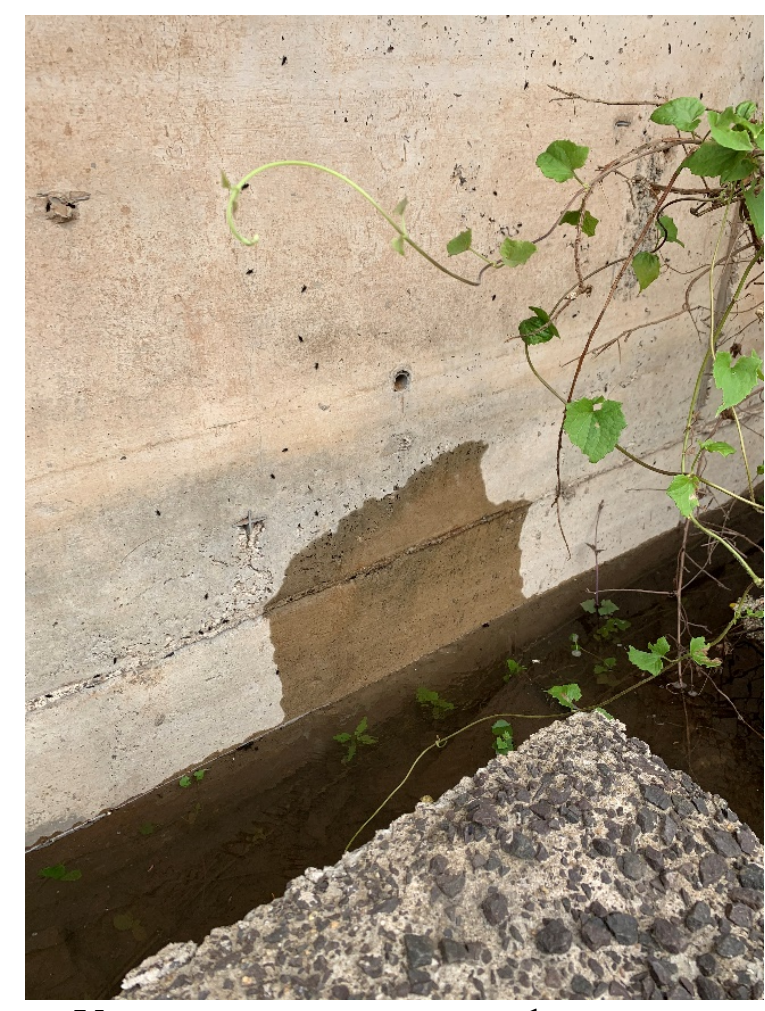

Vazamento na segregação do concreto

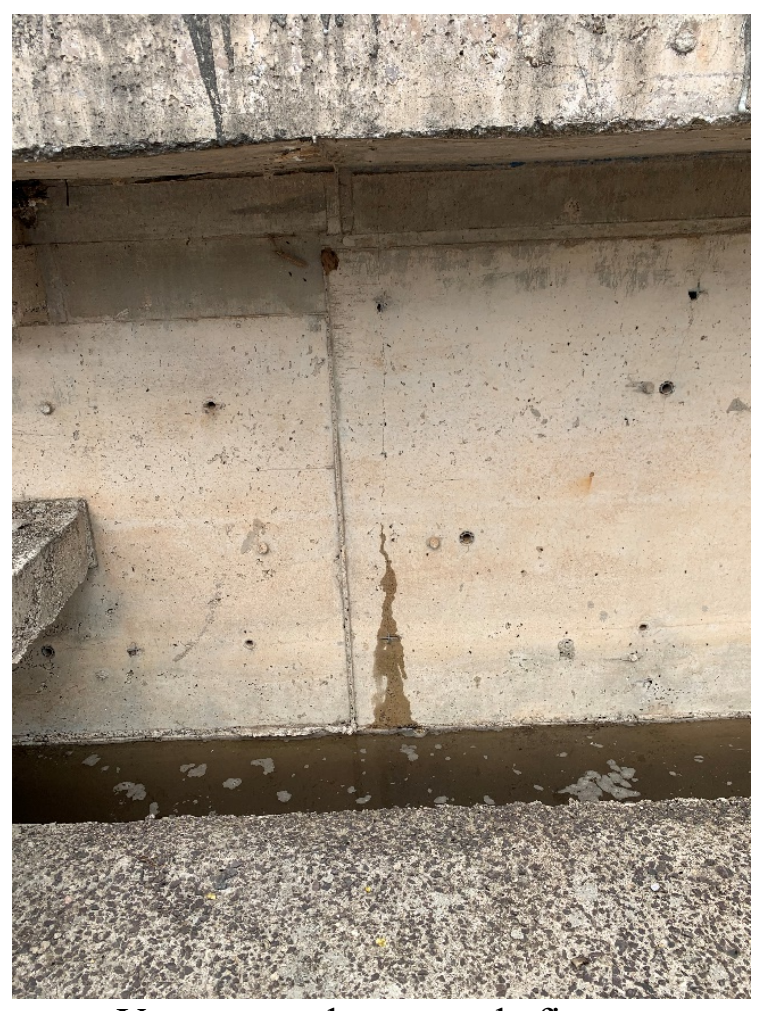

Vazamento de agua pela fissura

Figura 11. Locais com vazamento na parede 4 durante o teste de estanqueidade

Os pontos de vazamentos ocorreram pelas fissuras e nos locais com ocorrência de segregação do concreto.

Importante destacar que, como o nível de água não superou a altura de $60 \mathrm{~cm}$ e como as fissuras possui formação em toda a altura da parede, o vazamento de água se manteve apenas na parte inferior da fissura, compreendida na região de pressão da água.

Nas regiões de encontro da parede 4 com as paredes 1 e 2 também foram observados pontos de vazamento, os quais são apresentados na Figura 12. 


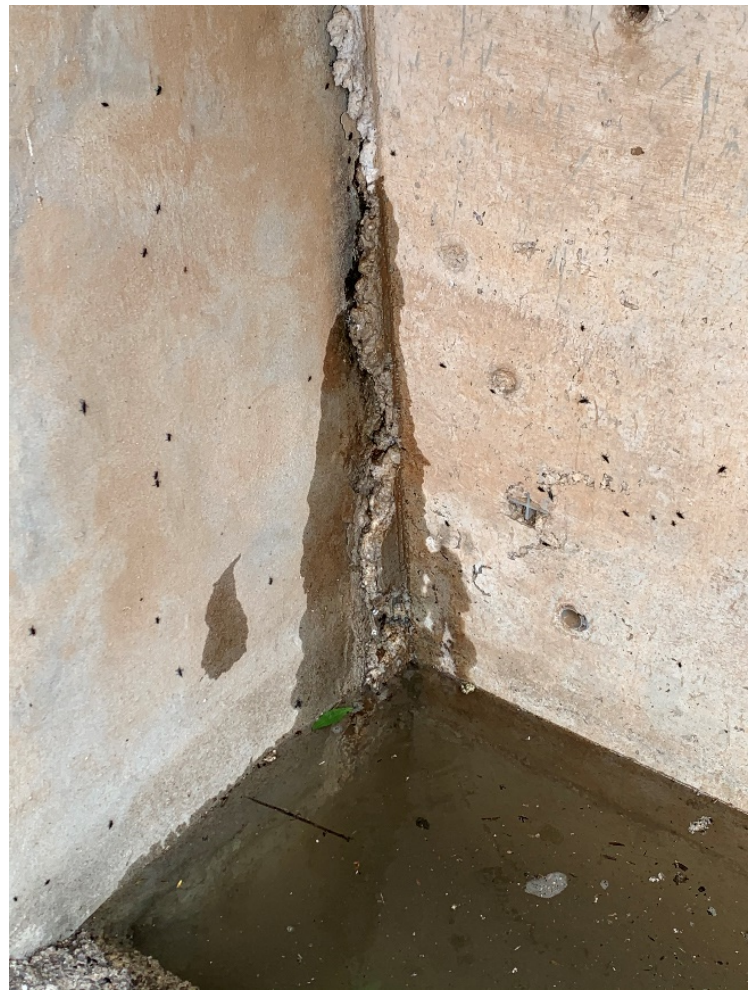

Encontro da parede 4 com a parede 2

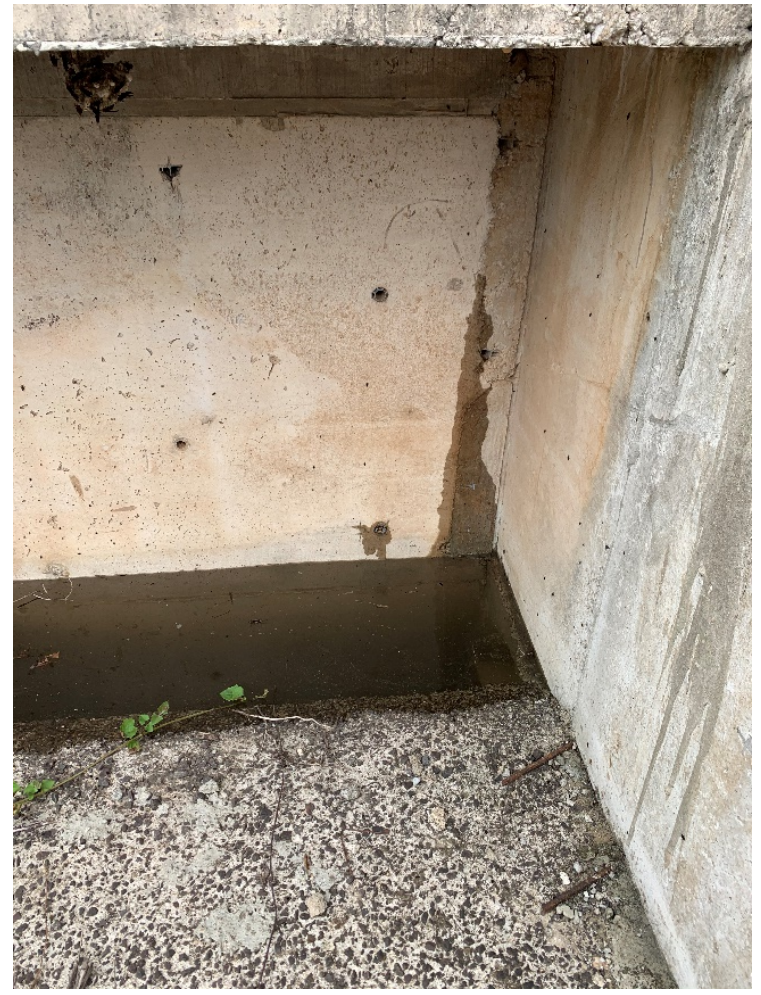

Encontro da parede 4 com a parede 1

Figura 12. Locais com vazamento na parede 4 na junta de concretagem

Nos locais de encontro da parede 4 com as paredes 1 e 2, foram registrados vazamento de água, estas regiões são caracterizadas em projeto como junta de concretagem, conforme processo executivo, a parede 4 foi executada posterior às paredes 1 e 2 .

Ao longo do período em que a água permaneceu no reservatório, não foram observados sinais de vazamentos de água nos locais sem ocorrências de manifestações patológicas.

Depois do esvaziamento do tanque, após 6 dias do enchimento, foi realizada nova vistoria, no qual não foram visualizadas surgimento de novas manifestações patológicos, tampouco aumento na abertura das fissuras.

Os resultados dos deslocamentos, determinados pelo equipamento topográfico, durante o teste de estanqueidade são apresentados na Figura 13. 


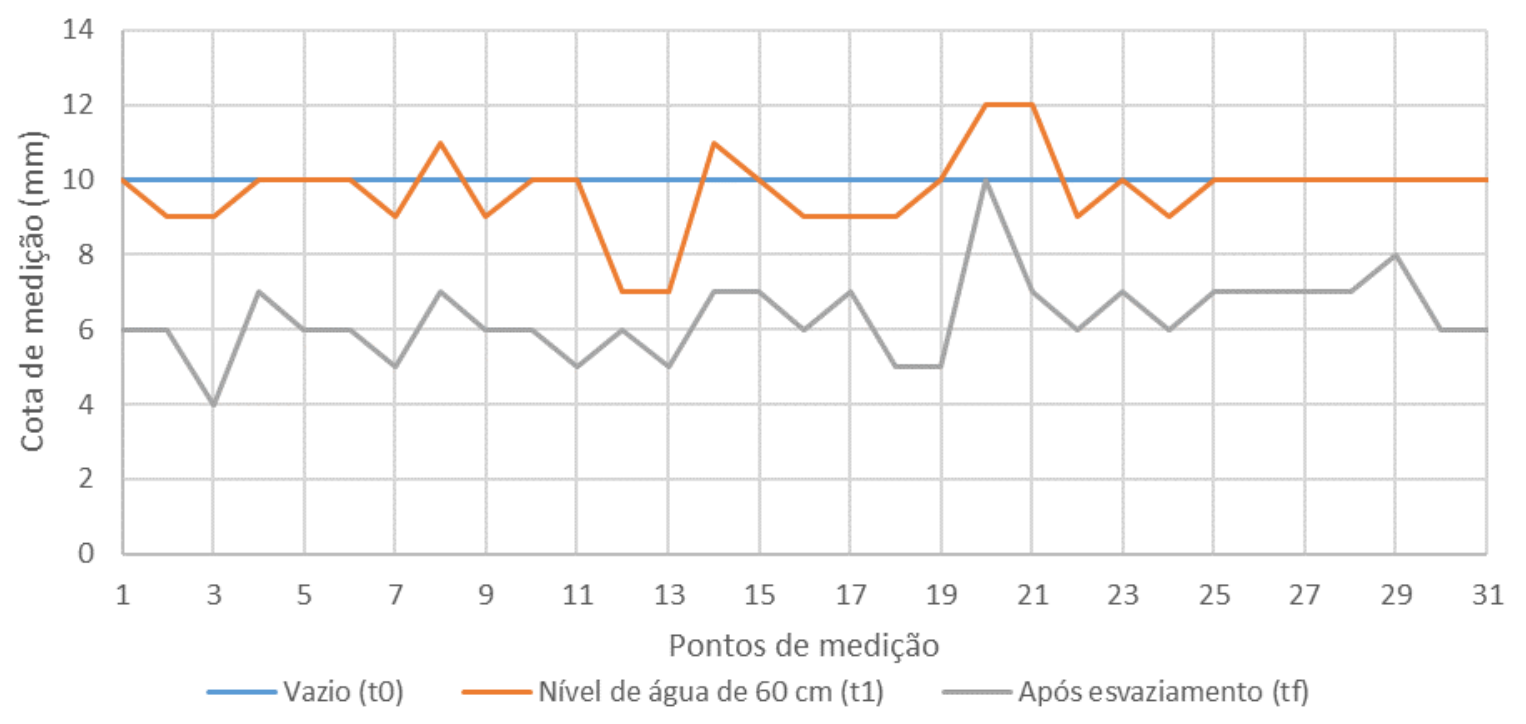

Figura 13. Resultados das medições do deslocamento

Os resultados das medições demonstram que o processo enchimento até o nível de $60 \mathrm{~cm}$ de água não motivou deslocamento na estrutura. No entanto, após o total esvaziamento, os resultados das medições indicaram movimentação média de $4 \mathrm{~mm}$ negativos, que satisfez o movimento de recalque. Entretanto, por não terem sido observados alterações na abertura das fissuras, entende-se que as alterações nos resultados do deslocamento, tenham sido geradas pela dificuldade na precisão das medições.

De modo geral, foi possível indicar que o teste de estanqueidade realizado de modo adaptado, não foi capaz de desenvolver alterações ou deslocamentos no elemento em estudo.

\section{CONCLUSÕES}

Como as fissuras estão concentradas nas paredes do leito de secagem, com configuração vertical e espaçadas regularmente são de maior abertura junto a borda superior da parede e à media que a fissura se aproxima da base a abertura diminui ao ponto de até desaparecer, entende-se que as fissuras foram originadas por retração impedida do concreto, pois a laje de piso do leito de secagem exerceu restrição de movimento na parede.

Após o teste de estanqueidade, foi possível confirmar que as manifestações patológicas de fissuras, por possuírem abertura superior ao estabelecido pelas normativas, não são capazes de manter a estanqueidade do tanque. Além do mais, os pontos com segregação do concreto, bem como as juntas de concretagem, também foram passíveis de escoamento de água, desenvolvendo com isto, prejuízos na estanqueidade do leito secante. Por consequência, as manifestações patológicas possuem carácter funcional.

Por fim foi possível indicar que o teste de estanqueidade, mesmo realizado de modo adaptado, determinou o desempenho à estanqueidade do objeto de estudo e não desenvolveu alterações ou deslocamentos no elemento em estudo.

Além do mais, o teste de estanqueidade demonstrou que a estrutura apresenta deficiências na função de estanqueidade, apenas nos locais com manifestações patológicas, o que remete à necessidade do tratamento das fissuras, além dos pontos com segregação do concreto e na junta de concretagem, para que a função de estanqueidade do tanque seja garantida. 


\section{REFERENCIAS}

Fédération internationale du béton (fib): Model Code 2010, final draft. fib Bulletin Nos. 65/66, Lausanne, 2013.

European Committee for Standardization (CEN): PN-EN 1992-3: Design of concrete structures Part 3: Liquid retaining and containment structures, Eurocode 2, Brussels, 2006.

ZYCH, Mariusz. Modification of the simplified method of crack control included in EN 1992-3. Structural Concrete, v. 17, n. 4, p. 553-563, 2016.

Stoffers, H. Cracking due to shrinkage and temperature variation in walls, 3rd ed., Delft University of Technology \& I.B.B.C., 23 (3), p. 68, Delft, 1978.

Seruga, A., Zych, M.: Thermal Cracking of the Cylindrical Tank under Construction. I: Case Study. ASCE Journal of Performance Construction Facilities, 29 (4), pp. 04014100-1-04014100-9, 2015. OLLIVIER, J.; VICHOT, Angélique. Durabilidade do concreto-Bases científicas para a formulação de concretos duráveis de acordo com o ambiente. 1th. Brazil: IBRACON, 2014.

CÁNOVAS, Manuel Fernández. Patologia e terapia do concreto armado. Pini, 1988. COMPANHIA RIOGRANDENSE DE SANEAMENTO. CORSAN. Manual de elaboração de projetos e construção de Estação de Tratamento de Esgoto. 2011.

THOMAZ, Eduardo. Fissuração em reservatórios, Revista IBRACON, São Paulo, n 4, p.19-23, agosto 2007. 